\title{
Knowledge Diffusion from China into Ghana's Agricultural Sector: Processes, Contexts and Success Variations Among Agricultural Sub Sectors
}

\author{
John Windie Ansah \\ Department of Sociology and Anthropology, University of Cape Coast, Cape Coast, Ghana \\ Email address: \\ john.ansah@ucc.edu.gh \\ To cite this article: \\ John Windie Ansah. Knowledge Diffusion from China into Ghana's Agricultural Sector: Processes, Contexts and Success Variations Among \\ Agricultural Sub Sectors. International Journal of European Studies. Vol. 4, No. 1, 2020, pp. 13-26. doi: 10.11648/j.ijes.20200401.13
}

Received: December 12, 2019; Accepted: January 3, 2020; Published: May 29, 2020

\begin{abstract}
Development literature show that when actors from different territories meet knowledge is likely to be shared in more relational and interactive terms. This argument forms the basis for interrogating the essence of knowledge diffusion from China into Ghana's agricultural sector in terms of forms, contexts, processes and success variations. The research was qualitative in nature with the deployment of exploratory research design. The study used data collection methods involving 8 interviews and 3 focus group discussions involving purposively selected individuals, groups, state and non-state institutions in the agricultural sector. The dynamics of knowledge diffusion from China into Ghana's agricultural sector, as the study found out, present certain unique patterns of non uniformity. Such non uniformities formed the basis upon which the knowledge diffusion processes could be understood and applied. Arrays of mediums were found as being used to diffuse the knowledge from China into Ghana's agricultural sector in the contexts of increasing degrees of technological advancement and stateinitiated policy arrangements. The study also found out that the successful diffusion of knowledge from one territory to another largely depends on the linguistic parity as well as foundational knowledge, adaptive power and innovative abilities of the actors in the recipient country. In all cases, the varied degree of diffused knowledge between the territories shows that the involvement of the state could be the defining factor in promoting knowledge diffusion.
\end{abstract}

Keywords: Knowledge Diffusion, Agriculture, China, Ghana

\section{Introduction}

Reports and academic studies conducted on agricultural sector show clear manifestations of capital mobility crystallized through foreign direct investment, trade and inventor mobility. The reports and academic studies show clearly that Chinese foreign direct investment, trade and inventor mobility into Ghana's agricultural sector could be located in such sub-sectors as industrial fish trawling industry, fishing, tuna fishing, aquaculture, vegetable farming, poultry production and the distribution of agricultural machinery and agro-processing [1-6]. Ghana's experience is a micro reflection of international and African agricultural development initiatives as part of the South-South cooperation agenda [2,3] with some beneficial outcomes to Ghana [5].

Analyzing the patterns of foreign direct investment and trade it can be observed that even though Ghana's open economy and the attractiveness of Chinese products by actors in the agricultural sector is one which allows trade in Chinese agricultural equipment to flourish, the Ghanaian economy remains unattractive to many land-based agricultural investments and agribusiness from Chinese MNEs [6].

However, as attempts are made to tease out the focus of this study as far as Chinese engagement in Ghana's agricultural regime is concerned, I discover, from the literature, certain truths which characterize major economic relations between countries. It has been established in the literature that when actors from different territories meet knowledge is likely to be shared in more relational and interactive terms [7].

Hence, in so far as countries engage in economic forms of interaction and development initiatives, including agriculture, knowledge sharing is likely to occur and may even manifest instantaneously and transparently $[8,2,3]$. In addition to [8] observations, [9] contends that much can be taught about how knowledge diffusion could produce development or underdevelopment within specific regions of the modern 
world. Further, [10], also establish that despite the effect knowledge diffusion might have in territorial spaces, such effects have been neglected quite often in recent literature which cover the topic of knowledge diffusion.

With specific reference to China's long march into Africa's agriculture, [11] clearly mentions that Chinese engagement with Africa in the agricultural sector signals a rebalancing toward boosting technology within which knowledge diffusion may occur. Given the trade and investment patterns of agricultural input from China into Ghana's agricultural sector it is clear that the presence of Chinese technology has become the central focal point around Ghana's food production activities are largely organized thereby supporting [11] argument. Putting it differently, it can be established, as a context, with the submission of [12] that just like capital mobility, knowledge diffusion enterprise has also been crystallized in trade, investment and inventor mobility. It therefore suffices to say that, the processes with which capital mobility is occurring constitute similar processes with which knowledge is being diffused from China to Ghana's agricultural sector.

Thus, as Chinese investments in Ghana grows, as trade volumes assume significant proportions and as inventor mobility becomes apparent knowledge about the Chinese products is likely to be diffused. In other words, as Chinese technology is seen to be introduced through trade, investment and inventor mobility it requires an interrogation of the dynamics with which the knowledge is transferred. By way of significance I find the quest to interrogate the issues surrounding knowledge diffusion because it is a sine qua non for the promotion of economic growth and social progress through rational choices, organizational efficiency, as well as social and economic equity [12-16]. The data will then be very useful for policy making particularly in the realm of agricultural mechanization and the indigenization of the manufacturing sector.

Some studies on knowledge diffusion from China into Ghana's agricultural sector have been carried. Notable one amongst them is what [5] executed. However, his study was limited to only officials in the agricultural sector who received direct-face-face knowledge from Chinese technical experts. This study, however, focuses on those who fall outside the purview of officialdom as far as the agricultural sector is concerned and how knowledge associated with Chinese capital mobility has permeated into the scope of their operations. On this score, the questions which may require attention are:

1. What are the traces of uniformity or otherwise in the patterns of diffused knowledge from China among the subsectors of the agricultural sector?

2. How does the knowledge get diffused in a more variegated agricultural sector?

3. Within which contexts is knowledge diffusion facilitated?

4. What are the structural impediments of knowledge diffusion from China into Ghana's agricultural sector?

5. How does Ghana's agriculture sector benefit from the existing patterns of knowledge diffusion?

\section{Knowledge and Knowledge Diffusion - The Conceptual Issues}

The notion of knowledge has appeared in much literature within philosophical and theoretical contexts. Even though the concept may not generate much controversy in definitional terms its nature and dynamic importance produces a platform of many perspectives.

[17] define knowledge as the 'intangible' resource which may be generated, used and transformed by multiple actors. From [13] perspective knowledge never exists in concentrated or integrated form, but solely as the dispersed bits of incomplete and frequently contradictory which all separate individuals possess.

[8] points out the contextual nature of knowledge. In his submission, knowledge has implicit and explicit context. Implicit knowledge, to [5], cannot be captured instantaneously, over time and space and it must be transmitted by personal contact - that is - via face-to-face communication, because it is often embodied while explicit knowledge can be easily articulated, transferred and saved and is often disembodied. As such, knowledge may not just be generated, used and transformed but it may be transmitted as well. Indeed, the mode of transmission is determined by the context within which knowledge is generated.

In classical philosophical and sociological writings, knowledge is considered critical to the progress of societies. They expressly suggest that knowledge is not an end in itself. But other writings on knowledge which could situate within the realm of political economy have also displayed its usefulness in unequivocal terms irrespective of the ideological stand - be it liberalism or Marxism. For example, [13] a neo-liberalist, concludes that the utilization of knowledge could generate ideas, inform decisions and construct rational economic actions among actors in any economic order.

Marx's argument about knowledge rightly expressed in his seminal writings also suggests the acquisition of knowledge about any economic order as significant to marking an end to 'false consciousnesses', hence forming the beginning for acquiring the 'true class consciousness - the path towards the liberation from economic exploitation.

Unlike [13, 14] who find knowledge as useful to the individual, groups and society at large, [18] situate the usefulness of knowledge from the organizational perspective and argue in that regard. To them, effective management of knowledge and innovation has become a key to corporate success, technology progress and economic development.

Fast forwarding the intellectual discourse on knowledge to the $21^{\text {st }}$ century, intellectual analyses on the usefulness of knowledge particularly in the economy, has been brilliantly summarized by [10] They argue that "knowledge can be recognized as one of the competitive advantages in a globalized economy" (p. 1).

[10] Extend their arguments further by suggesting two closely linked facets of knowledge which promote social progress including (a) the creation of knowledge and (b) the diffusion of knowledge. The linkages between the determinants are far more expressed with the introduction of ICT which does not only 
favor the process of knowledge diffusion but also enforces the creation of knowledge, indirectly [10] as well as being an indicator of created knowledge.

Knowledge diffusion happens when knowledge is communicated through certain channels from members of one social system to another social system who do not share the same national territorial boundary.

As stated by [19] knowledge diffusion is hard to measure, both practically and theoretically. This is because "knowledge flows are invisible; they leave no paper trail by which they may be measured and tracked" (p. 2). Providing further insights in a rather metaphorical fashion, [10] argue that diffusion process itself can be imagined as an epidemic or as a hierarchical phenomenon. The first assumes that from a given source knowledge diffusion spreads uniformly over space. The latter instead interprets knowledge diffusion as depended from agglomeration phenomena: Knowledge first flows from the source to agglomerated areas and then with a certain delay to peripheral economic areas. Hence, knowledge creation and knowledge diffusion are not only context or problem based dependent, but further have a time and a spatial dimension.

Summing up, knowledge is a non material resource which, as possessed by or dispersed among individuals, is generated, used, transformed and transmitted to promote social progress through rational choices, organizational efficiency, as well as social and economic equity.

\section{Theoretical Orientations}

Quite a number of theoretical ideas have been put forward which define the relationship between knowledge diffusion and economic development within geographical contexts. In the first place, it is established in the literature that the diffusion of knowledge, and its attendant possibility of generating economic development, occurs through three mediums.

The first medium is trade [20-22]. The second is through foreign direct investment (FDI) [23-24] and the third is personnel or inventor mobility [25]. In the literature, proofs are offered about how knowledge diffusion is enhanced by each medium, separately. However, these arguments are limited as they fail to recognize that these mediums can operate simultaneously. They also fail to recognize that the role of these mediums in enhancing knowledge diffusion is more dynamic and complex than the simplistic and isolated manner with which they have been argued.

[12] Corrects the analytical deficiency in his early works on knowledge diffusion by showing the complex and dynamics relationship between the three mediums. Incorporating trade, FDI and inventor mobility and comparing their effects on knowledge diffusion, [12] makes it apparent that FDI and inventors mobility enhance knowledge diffusion but the flow of knowledge reduces when the technological portfolios of two countries are similar.

Comparing the effects of the three mediums, he argues that inventor mobility is the most effective medium for knowledge diffusion when the technological portfolios are of two countries are completely different while trade becomes more effective and balanced when the technological portfolios are completely identical [12]. Hence, it is established, as the literature suggests, that the extent to which knowledge is diffused through these mediums largely depends on the similarities and differences between the geographical areas between which a particular kind of knowledge is being diffused.

On the contributions of knowledge diffusion to economic development, [26], in a simplistic fashion, argue that knowledge externalities provide relevant explanation for spatially uneven economic and innovative performance. Moreover, [17] contend that knowledge is important as its adoption by local firms would enable them to move up a value chain system.

One of the expressions of knowledge diffusion is technological transfer. This is true because knowledge is embedded in every technology. At the same time, knowledge diffusion can be beneficial to economic development through technological innovation in a host entity (at national and local level), because the entity can take advantage of both internal and external knowledge to strengthen its innovational capability in so far as spillovers arising from technological innovation can cross national boundaries [27-29].

In this regard, knowledge-intensive activities become fundamental for efficiency, improved competitive advantage and economic performance following the distinctive patterns of geographical distribution $[15,16]$. In addition, regions involved in trade and other forms of production and distribution networks may also benefit from channels of international knowledge diffusion which complements and enriches locally produced knowledge $[30,12]$.

Juxtaposing knowledge diffusion with regional disparities Henderson, Coe, Hess, Yeung, and Dicken (2002) establish that diffused knowledge cut through regional and national boundaries in highly differentiated ways and create structures that are 'discontinuously territorial'. But the process of knowledge diffusion is done consciously and strategically as firms rationally locate other firms in different geographical areas (host regions) where the activities of the former firms could be carried out effectively [31]. Additionally, firms may locate some geographical areas as useful in so far as they are needed to facilitate the penetration of important markets. For this reason, bringing the role of geographical disparities into the knowledge diffusion-economic development nexus, [28] was quick to add that the effect of innovation on national comparative advantage depends on the geographic scope of its diffusion.

Extending the earlier arguments in the literature, studies by [32] have shown clearly that the success of host regions in capturing the advantages of knowledge diffusion, expressed through innovation, crucially relies on fundamental and structural characteristics. This argument serves as a macrocosm of assertions raised about by [33] that technology, as an expression of knowledge, is embedded in social, economic, cultural and political contexts. These structural characteristics or contexts, [32] noted, range from related local knowledge-base and the absorptive capacity of social and institutional infrastructure.

Subsequently, studies by $[34,16]$ were carried out and their findings corroborated the afore-mentioned assertions. However, they contend that other conditions, these structures, 
play out in translating diffused knowledge into meaningful developmental outcomes.

On the part of [16], translation of the knowledge into visible outcomes in terms of productivity depends of how properly the knowledge is diffused to the recipient. Beyond the idea of correctly diffusing knowledge, [34] argue that the current understanding and best practices in scientific knowledge diffusion demands a multi-stakeholder and a multi-disciplinary in an integrated framework. This is a position which was rightly supported by [35] who argue that a successful knowledge diffusion regime relies on a more dynamic, participatory, collaborative system and the one that engages the knowledge end-user in the process.

Closely connected to knowledge diffusion is knowledge adaptation. To [36] the process of adapting knowledge are complex and nonlinear thus the learning process requires heterogeneous and diverse processes in both horizontal and vertical fashions. What was missing in this argument was what could trigger the heterogeneity and diversity of the learning process. By locating the trigger, [17] extend [36] arguments. Perhaps this is one of the few scholarly works which provide political economy insights in the knowledge diffusion. They pinpoint trade liberalization, good market infrastructure and favorable government policy as those economic conditions which allow the heterogeneity and diversity of the learning process to flourish.

Nonetheless, all these contentions represent one truth. They suggest that the innovation process and economic development which emerge from knowledge diffusion are the result of complex patterns of interactions between a number of actors acting together according to common norms, practices and historical inheritance [20,32].

The reality, nevertheless, is that the common norms and practices change in time and space. It is in this regard that [37] contends that the process of adapting knowledge, as a social process, is transforming and individuals or groups may alter and adapt their knowledge in response of the changing intentions, opportunities and circumstances. These changes include ecological circumstances and economic situations [17] as well as political and social structures.

\section{Study Orientation}

The major objective this paper was to discover the patterns of knowledge diffusion from China into Ghana's agricultural sector.
The study was strictly qualitative and thereby gathered the information about the diffused knowledge as experienced by the actors in the agricultural sector. This method was preferred to the quantitative method given the fact that knowledge diffusion is hard to measure, both practically and theoretically. This is because "knowledge flows are invisible; they leave no paper trail by which they may be measured and tracked" (2) [19]. Moreover, given the fact that no such study, in terms of research participants and scope has been carried out this study decided to assume an exploratory stance so that is would create a research foundation for which quantitative studies would be conducted.

\subsection{Target Respondents and Sampling Technique}

In all, 48 actors drawn from the three main sub sectors of the agricultural sector were grouped into three categories according to the nature of group formation. They included associations, non state institutions, and individuals. The actors were recategorized according to their statuses in the agricultural sector. They were then given labels as producers, distributors and technical experts. These groups were selected on purpose in lieu of the reality that they are at the receiving end of the Chinese trade, foreign direct investment and inventor mobility.

The groups, institutions and individuals were selected when experts in the crop, fisheries, and animal husbandry sub sectors acted as lead persons. Knowledge about their existential presence in the Ghana's agricultural sector was obtained through some key experts and officials in the various subsectors. Some were also obtained through other groups and individuals. Information about their presence came up during the interviews of those whose names had been mentioned by the experts. Among these non state institutions, phone calls were made by way of formalizing contact. While some agreed on the interview exactly on the day the request was made, other scheduled the interview appointment on a later date. They opened up for the interviews because of the credibility of the source of reference I made regarding my knowledge of the presence.

The Agricultural Engineering Services Directorate was added to the list research institutional participants because of its unique role of testing the quality the agricultural equipment from China and other countries. This role brings them in direct contact with the equipment hence possibility of experiencing knowledge diffusion.

Table 1. Research Participants.

\begin{tabular}{llll}
\hline Agricultural Actors & Associations & Institutions & Individuals \\
\hline Producers & Poultry farmers, aqua ${ }^{1}$ culturists, commercial and & & Agro-chemical $^{3}$ producer \\
& peasant farmers, industrial fishermen & RST, agro-chemical ${ }^{2}$ retailers, poultry feed & \\
Distributors & & supplement and drug retailers & \\
Technical Experts & & AESD & $\mathrm{AESD}^{2}, \mathrm{RST}^{3}$ \\
\hline
\end{tabular}

Source: Author's own construction.

\footnotetext{
1 Planned participants.

2 First-person referral participants.

3 Second-person referral participants.
} 


\subsection{The Data Collection Methods and Techniques}

Official letters were written and handed over personally to the front desk executive of the AESD. Upon reading the content of the letter the front desk executive assigned me to an official who was well placed to offer information on knowledge diffusion from China to Ghana's agricultural sector. Contact number was taken for a follow up on the director's approval the director. Afterwards, an appointment date was scheduled. The interview was carried out on the appointed date. Two officials in that unit were available on the day for the interview. That enriched the quality of the responses and the data thereof.

For all these groups, institutions and individuals information about the patterns of knowledge diffusion associated with Chinese mobility was drawn out from the research participants through in-depth interviews and focus group discussions which were carried out. The setting for the data collection was the respective work places of the research participants which generally took between one hour and an hour and a half. The information was recorded in all cases as the interviewees had granted the opportunity to do so. The research participants were asked to provide their experiences and encounters and documentary evidence through which they had found Chinese experience as a tool for knowledge diffusion in their realm agricultural operation. To ensure objectivity, research participants were encouraged and restricted to concentrate on the knowledge they had acquired relative to Chinese capital mobility into the agricultural sector alone. The main issues which were brought out for discussion included:

a) How they came into contact with the Chinese capital mobility

b) The content and nature of the knowledge acquired

c) The mode with which the knowledge got diffused from China to them

d) The means with which the knowledge got diffused from China to them

e) Through what contexts is the knowledge diffused and promoted?

f) The quality of the knowledge embedded in Chinese capital mobility vis-à-vis the capital mobility from other countries

g) The impediments to the promotion of the diffused knowledge from China

h) How the knowledge has improved the quality of the production and service delivery?

\subsection{Analysis}

The obtained data were transcribed, coded and classified into categories. After this the transcribed data was extracted manually as relevant texts from the transcriptions were sorted, highlighted and marked with a label of one of the key items embedded in the original thematic framework. The framework included the content and the nature of knowledge as well as the means of transmission as they occurred among the various sub sectors of the agricultural sector. Subsequently the texts with content which showed the traces of knowledge diffusion were further categorized into sub themes based on the mode of knowledge diffusion, usability of the knowledge diffused, transferability of the diffused knowledge as were ascertained. In the course of the analysis key sub themes were discovered from the data and subsequently created using the process of recontextualization.

Using the theoretical framework on knowledge diffusion, I sought to analyse the contexts within which knowledge was being diffused and the contexts within which it was not. At this certain social processes, cultural arrangements, economic conditions and political organizations became the centerpiece around which the explanation of how farmers and fishermen and other actors in the agricultural sector encountered, received, adopted and applied the knowledge diffused or not diffused as capital mobility was spread. In this regard reason, the study employed the constant comparative analytic strategy where the fundamental social processes which characterized their descriptions of the Chinese capital mobility and knowledge diffusion as either useful or a threat, within and among the subsectors were unearthed. In addition, the phenomenological analytic strategy was used to analyse the lived experiences of as many actors in the agricultural sector as people [38] who are directly or indirectly affected by knowledge diffusion from China and how such experiences led them to admit whether the Chinese presence was a constituted a means towards acquisition of knowledge. Narrative analysis was also used as participant, especially members of associations were made to share and recount their experience of event that were closely connected to use of Chinese agriculture-related product in so far as it facilitated knowledge diffusion from china or not.

To gain and retain a grasp over the overlapping relationship between the respondents' narratives and my interpretation, some amount of reflexivity was introduced in terms of which associated myself socially and intellectually in relation to responses about how Chinese capital mobility has occasioned knowledge diffusion [39].

\section{The Data}

\subsection{Knowledge Diffusion in the Food Crop Production Sub-Sector}

It should be emphasized that the knowledge being produced by China as evidenced in the products available in Ghana either by trade (ie importation) or by FDI is equally being produced by other countries. Indeed, some of the products are becoming means through which knowledge is diffused from China into Ghana's agricultural sector. Cases in point are products in the agrochemical industry as well as agricultural machinery being 
produced by China. In the analysis mention is made about countries from which China obtained knowledge as far as the production of certain agricultural inputs is concerned. Bringing the role of the other countries which produce similar products as the Chinese agricultural inputs into the analysis is useful because their inclusion would enhance the appreciation of the importance and understanding of knowledge diffusion in a globalized context. Besides, analyzing their roles will equally help situate the issue of Chinese product quality and its political economy implications thereof into proper context.

\subsubsection{Knowledge Diffusion Associated with}

Agro-Chemicals Produced by Chinese Firm in Ghana

Data gathered from interviews with an agro-chemical retailer led to the discovery that knowledge diffusion from China has been experienced in the agro-chemical industry. Evidence gathered from some reveals that some young Ghanaian entrepreneurs had gained considerable know-how about agro-chemicals particularly the chemical formula required for their production. As a follow up on an interview with the young entrepreneurs, they indicated that they obtained the knowledge though constant interaction with the agro-chemical produced by the Chinese subsidiary in Ghana, known as Wynca Sunshine (Ghana) Agric Products \& Trading Company Limited. The brand name for the company's agro-chemical products is WYNCA. The young Ghanaian producers of agro-chemicals who produced goods similar to what Wynca Sunshine (Ghana) Agric Products \& Trading Company Limited produces had actually brand named his agro-chemical as 'TSUNA'. As such unlike [8] who indicated that knowledge may be diffused through personal and face-to-face contact, the process of knowledge diffusion to the agro-chemical producers show that knowledge may happen through virtual means.

Indeed, the point must be established in the understanding of knowledge diffusion within globalized contexts that the knowledge embedded in the agrochemical production found in the WYNCA products was obtained from the knowledge embedded in agro-chemicals produced from South Africa with a brand name, CHEMICO. It is in this sense that knowledge may be seen to be produced and transformed by multiple actors [17] in a linear fashion.

Given the fact that the young Ghanaian entrepreneur had produced similar agro-chemical as that of Wynca Sunshine (Ghana) the knowledge derived from the South Africans by the Chinese could be seen to have equally been diffused into Ghana thus reinforcing the creation of knowledge, indirectly, [10, 40] from South Africa. For example, as indicated from a retailer in the agro-chemical industry. He maintains that

"Chinese agrochemicals started coming in 2002 but previously farmers had been exposed to only agrochemical imported from South Africa and the WYNCA people were learning from the CHEMICO producers".

This was also visible in the fact that one could even find the similarities in the names of the products. This is outlined on Table 2

Table 2. Agro-chemicals from China and Substitutes from South Africa.

\begin{tabular}{lll}
\hline Type of Agro-chemical & Chinese Brand & South African Brand \\
\hline Herbicide & Rezim & Atrazim \\
Insecticide & Sunpyrifos & Dursban \\
Insecticide & Lamdakin & Pawa \\
Herbicide (for pineapple) & Caritek & Chemopax \\
\hline
\end{tabular}

Source: Author's Construction.

Such knowledge from the South African agro-chemical firm can be regarded as what [8] describes as explicit knowledge because it is easily being articulated, transferred and saved and is often disembodied. This observation equally demonstrates that knowledge never exists in concentrated or integrated form, but solely as the dispersed bits of incomplete and frequently contradictory which all separate individuals possess $[10,40]$.

Judging from the modes of knowledge diffusion in the agro-chemical industry from South Africa to China and subsequently to Ghana confirms the first assumption in knowledge diffusion which holds the view that knowledge diffusion spreads uniformly from a given source over space. In this sense, knowledge about agro-chemicals first flows from the source to agglomerated areas such as South Africa and then with a certain delay to peripheral economic areas such as Ghana. Hence, knowledge creation and knowledge diffusion are not only context or problem based dependent, but further have a time and a spatial dimension [41].

However, knowledge diffusion from the Chinese to the Ghanaian could be observed to be taking place in a manner where the knowledge embedded in the production of agrochemical was officially undisclosed by the knowledge producer. As rhetorically asked by an agro-chemical retailer,

"You have been there before. So you see them processing... What do they teach you? Do they teach you anything at all about how they do their?...: That one dieer...they won't teach you. They don't teach you. Why should they teach you"?

Significantly, therefore, there is an indication that knowledge diffusion may happen without the consent of the knowledge producer. In this regard knowledge can be diffused unknowingly from the knowledge creator. As found in the case involving the young Ghanaian entrepreneurs who had produced an agro-chemical similar to that of the Chinese, they gathered knowledge about the Chinese agro-chemical without the consent of the Chinese agro-chemical Chinese industry. As intimated by an agro-chemical retailer,

"He did biochemistry at the Kwame Nkrumah University of Science and Technology so when the Chinese products started coming in he also gathered some knowledge and did his own analysis and saw some active ingredients that he needs".

From the responses, the possession of a higher level of education by the Ghanaian who was able to produce an agrochemical similar to the Chinese agro-chemicals played a role in his ability to adapt to the diffused knowledge. This shows 
regions involved in trade and other forms of production and distribution networks may benefit from channels of international knowledge diffusion which complements and enriches locally produced knowledge [27-30, 12]. This also resonates the view that the effectiveness of knowledge diffusion depends on the absorptive capacity of the recipient of the knowledge which are attained through, in the words of [42], "upgrading of skills and abilities at various levels" (p. $8)$.

However, despite the unconsented nature with which the knowledge about agro-chemical production was diffused to the young Ghanaian agro chemical producer, it cannot be denied that the channels of international knowledge diffusion of WYNCA have worked to complement and enrich locally produced knowledge subject to high foundational knowledge which improved absorptive capacity.

\subsubsection{Knowledge Diffusion Associated with Agricultural Farm Machinery from China}

Unlike the agro-chemical industry in which knowledge diffusion took place without the direct contact and consent of the knowledge producer, the process of knowledge diffusion may occur through a direct contact with and the consent of the inventor suggestive of the fact that knowledge can be diffused through direct personal contact [8] though not the implicit knowledge type. When the engineers at the Agricultural Engineering Services Directorate (AESD) were engaged in a focus group discussion, such a discovery was made. These engineers' main responsibility is to assemble imported agricultural machinery from countries such as Japan, the Czech Republic, India, Vietnam, Thailand and China clearly indicative of the [13] suggestion that knowledge exists but solely as the dispersed bits and incomplete of all entities. By extension, they perform another task by testing the suitability of foreign agricultural farm machinery to Ghana's topography and soil structure and make technical recommendations for their use by farmers. In this respect, it is not the knowledge production alone which could be seen be contextualized as suggested by [41] but the contextalization is found also in terms of its application.

With the information obtained from officials at the Agricultural Engineering Services Directorate, through an interview, it was noted that the Chinese machines which were available, to the knowledge of the Ministry of Food and Agriculture, include foton harvesters, maize pickers and power tillers. Officially, the first Chinese agricultural machinery to be imported into Ghana under the auspices of the Ministry of Food and Agriculture was the Shanghai tractor which first arrived in Ghana in 1997. Since then Ghana had also taken delivery of other machinery such as power tillers, tricycles and combined Yeu Han Gen combined harvesters. The last sets of new consignments of agricultural machinery arrived in 2010 and have been on the Ghanaian market since then.

It will be instructive to note that prior to the importation of Chinese agricultural machinery the Government of Ghana had been importing agricultural machinery from other countries such as Brazil, Japan, the Czech Republic, India, Korea Thailand, Britain, United States of America and Poland. These represent clear indications that the structural foundations of knowledge diffusion involve country-switches in terms of which the origins of the agricultural equipment used in Ghana's crop farming subsector through which knowledge is diffused are seen to be varied. Hence, knowledge is being generated by multiple actors [17]. However, suffice to say that with regard to tricycles, China has been the sole distributor.

From a political economy point of view, the countryswitches with regard to the origin of agricultural input which have been expressed as a political decision have been largely attributed to the cost of the machinery. In this regard, economic circumstances may limit the scope and options in terms of the multiplicity of origins of knowledge. This was clearly elucidated by the officials and engineers from the Agricultural Engineering Services Directorate as well as the importers of Chinese agricultural machinery, notably RST Company Limited.

An official in the Agricultural Engineering Services Directorate said,

"Of the top of my head I will say cost. Personally it will be difficult to say that they Chinese ones were not good or they were good but at least what in know is that theirs is always the cheapest in most cases and that makes it attractive to people"

The operations manageress of RST, importer of Chinese agricultural equipment also said

"we look at the cost involved for the poor farmer to be able to afford it that is why we do source from there first".

The importation and distribution of Chinese agricultural machinery has operated under two models. The first is the Government of Ghana (GoG)-supported model and the second being the private-importer distribution model. Under the GoG model, there is a bilateral arrangement between Ghana and China where Chinese machinery are imported by the Ministry of Food and Agriculture on behalf of the GoG and then distributed to farmers to buy on hire purchase basis.

Under the private-importer distribution model a private distributor imports the Chinese machinery. Notable private distributors include Motorking Company Limited and RST Company Limited. Under this model, the AESD's responsibility is to conduct tests and inspections to ascertain the suitability of the Chinese agricultural machinery for Ghana's topography and a soil structure. When the machines are found to be suitable they are recommended to farmers to purchase. Practically, AESD provides the contact numbers of the importers which distributes the Chinese agricultural machinery which have been found suitable to farmers to use on their farms. In this regard the AESD serves as a medium through which the Chinese imported agricultural machinery are popularized. The role of AESD reflects the essence of state-directed developmentalism; that political economy trajectory which requires the state to provide technical support for private actors.

Zooming the analysis into the process of knowledge 
diffusion from China into Ghana's crop farming agricultural machinery industry it takes a form as recounted by an official of RST. She states,

"what happens is, fortunately, when we are buying a machine and we know nothing about it, we bring the Chinese technologists and we all learn. We do some here we do some at the practical side especially the rice milling machines. We do the installation with Chinese and the Chinese train us to there"

In this case, in addition to the point as earlier on established that knowledge diffusion is taking place with the consent of the knowledge producer taking place within a face to face context, there is also a clear exhibition of inventor mobility accompanying trade as part of the knowledge diffusion enterprise from China into Ghana's agricultural sector.

However, just like it occurred in the agro-chemical industry where local producers received knowledge from the knowledge producer in an unconsented way a similar phenomenon was observed in the agricultural equipment industry. Using some local artisans produce the parts of the Chinese-imported machinery for sale to farmers as reference points the RST official hinted that

"They [local artisans] just looked at one and fabricated it and the people there prefer it because it is very affordable".

However, unlike the agro-chemical which was regarded as efficacious the same could not be said about the parts of the agricultural machinery. As the RST official further indicated, making reference to experiences of the farmers

"even back north in Tamale, there is a local manufacturer.

People buy his 50 Ghana instead of buying this for 300 Ghana and in a day they can change the parts thrice or 4 times. It is just 50 Ghana as compared to this which costs 300 Ghana. But they claim they change it twice or thrice so that makes it GH\&150 Ghana. So when you buy this which lasts for more than a month at GH $400 . . . "$

This could be as a result of the fact that the level of knowledge in the agricultural equipment required to produce its parts is higher than the level of knowledge required to produce a similar agro-chemical. Besides, the local agrochemical producer had an advanced foundational knowledge unlike that of the local producer of the parts which was low.

Hence, the difference in the degree of impact of the knowledge diffusion could be attributed to the varying levels of sophistication associated with the products and then to an extent the varying levels of foundational knowledge among the local producers.

From the responses, the acknowledgment of relevance of foundational knowledge for effective knowledge diffusion process was found to be visibly emphasized in this context. The official from the RST made it clear in her response as follows

"We do go to the technical schools. And pick the final year students. When they come, we also train them on the job. With the on the job training, we travel with some and leave some behind. We give them a year and if you are unable to pick up within a year we let you go but if you pick up, we maintain you. And when we maintain you, we give you the opportunity to do part time at the polytechnic (now technical university)",

The decision to select students from the technical university could be seen as a rational decision given the fact, as raised by [32] that related local knowledge-base and the absorptive capacity determine the success of host regions in capturing the advantages of knowledge diffusion. Moreover, the Chinese decision to move their experts to train the technicians hauled from the technical universities could as a way of ensuring that the machines are efficiently to achieve optimum benefit thus could be regarded as conscious and strategic. This decision typifies [31] observation that firms rationally locate other firms in different geographical areas (host regions) where the activities of the former firms could be carried out effectively.

With specific reference to the process of knowledge diffusion offered to Ghanaian engineers in AESD two things spanned out. First, process of knowledge diffusion was found to be similar to the process offered to the technicians in RST. The second discovery which is of importance at this point was the process of knowledge diffusion offered to Ghanaian engineers in AESD, just as the technicians of RST, was fundamentally different from what the other countries did. For example, in the case of the Czech Republic, Ghanaian engineers were offered the factory floor type of training where they are given firsthand knowledge about how machinery is produced and assembled.

In the case of China, however, as one of the discussants mentioned,

"We just go for seminars at China and so during the field demonstrations they will send you to local market so you will find the machines so they will explain it to you. This is that machine, this is how it works. They will give you brochures. They have camps where teach mechanization. They have training programmes and when you go there they are now going to teach you how to plough and how to harrow and so those things".

The intentions of these training programmes were to equip the engineers with the need skills to repair further teach farm operators how to use the equipment and then aid in repairs of these machinery in the likely event of a breakdown.

An official from the AESD further indicated that the invitation of engineers from Ghana to China is also for marketing purposes, somewhat. She indicated

"The trips were for the promotion of technology. They do invite our people to make them aware of the machines. They do that because they want to want to penetrate African markets but not like training that is supposed to add value to what you know already"

From the responses it is clear that the intentions of the process of knowledge diffusion from other countries particularly in case of the Czech Republic are broader than the intentions of the Chinese. The comparison shows how narrow the scope of knowledge offered by Chinese knowledge producers is and therefore shows how seemingly 
reluctant Chinese may be in the knowledge diffusion enterprise. It clearly shows the real economic interests that are associated with this knowledge diffusion enterprise as regards the Chinese agricultural machinery. This raises policy issues as regards the kinds of negotiations the Government of Ghana enters into as part of the bilateral agreement between Ghana and China and the need to consider the fact that what technicians and engineers learn from Chinese agricultural machinery is not sufficient to aid any industrial transformation relative to the crop farm subsector.

From the responses, it is also evident that even though [12] mentioned that knowledge diffusion may occur through inventor mobility, the case of Ghana's experience show that knowledge diffusion may also occur through trainee mobility. This was evident in the responses of the engineers in the Agricultural Engineering Services Directorate, one of the discussants mentioned.

In terms of the content of knowledge diffusion the discussants indicated that the knowledge obtained from the Chinese machinery is not fundamentally different from the knowledge they obtained from the Japanese machinery.

"The things I learnt in China when we visited were basic things. Before the person leaves here he is already highly knowledgeable in the on the equipment on how to use and assemble the equipment. Most of the things we are taught are already known by us. In some cases some of us even become tutors in the sense that the person taught will rather end up teaching other people".

Hence, even though knowledge diffusion had taken place in the crop farming machinery industry it preceded the introduction of Chinese machinery. Much as the knowledge acquired by the engineers is high to the extent that they could assemble fully knocked-down and partially knocked-down machinery and then modify equipment to suit the Ghanaian soil conditions the knowledge was acquired by virtue of their exposure to Japanese machinery and Czech Republican machinery. On this note, one of the discussant openly expressed that:

"Our contact with Chinese equipment has not added any new knowledge to what we already know about the agricultural machinery which has been imported from either Japan or the Czech Republic".

Hence, the potential of Chinese machinery in enhancing knowledge diffusion into Ghana's agricultural sector has been non-existent. This observation contradicts the arguments by [20-22] that knowledge diffusion would occur through trade. This is largely attributed to the fact that the technological ideas underpin the Chinese machinery is not any different from the Japanese machinery. As one of the discussants said,

"In these you either employ hydraulics, mechanical or you combine both. So before you get to foton harvesters you would have experienced the mechanical linkage between the Chinese equipment"

Indeed, the responses from the discussant even suggested that the Chinese adopted Japanese technology with regard to the agricultural technology. When they were asked to compare the quality of Japanese machinery and Chinese machinery one other discussant said, metaphorically, as follows:

"When I compare the equipment coming from Japan and the ones coming from China I can say that it is like a father and a son. The Japanese equipment is higher than the Chinese. The Chinese learnt from the Japanese so the Chinese equipment cannot match the equipment from Japan",

It is thus obvious that though knowledge has been diffused from China its relevance to the agricultural sector in terms of promotion of technology was of no effect. Indeed the Chinese technology is considered of lower standard than some of the other countries. This is also clearly evidenced in the fact that some products that have been produced by Ghanaian engineers at the AESD and the Adaptive Trial Station were borne out of the knowledge they acquired from the machinery from the Czech Republic. An official provided evidence as follows:

"even in this workshop we have started producing our 'slashers' which we sell to the local market. Se we are not involved in buying and selling but they are mostly smaller machines; we haven't been too successful with bigger machines for example tractor. We do this with the adaptive trial station which is a bigger workshop. We are trying to build a local combined harvester; we have been producing the parts in bits but we are not done yet".

The official from RST confirmed this truth. She indicated that, in some cases, RST is compelled to source the agricultural machinery from other countries in order to acquire high quality agricultural machinery. As evidence to this claim the official mentioned that

the Chinese you have to remove one part at a time so if you want thresh maize, even with the maize, the de husking it you have to remove certain parts, put in other parts to shell. The Indian one immediately you start, spark the machine it's like plug and play what you put in there is what it will produce for you

Even in cases where equipment is considered as being of high standard, it only equals the quality of other countries; the quality is not higher than the quality of other countries. Using Vietnam as a case in point, the official from RST maintained that

"the quality of the rice milling machine maybe when you compare it to the rice mailing machine from India and Vietnam you can say that the quality is the same"

In all these narratives it seems that an economic motive with regard to cost is the driving force to the importation of Chinese agricultural machinery. Hence much as cost may serve as a source of attraction, the quest for effective knowledge diffusion for crop farming machinery may require the consideration of other origins with higher technical efficiency than the Chinese.

From all the analysis and as the AESD engineers have clearly established knowledge diffusion from Chinese has not been worthwhile. By implication, if RST for example had concentrated on agricultural machinery from other countries 
other than China, the knowledge acquired from the Chinese instructor would have equally been acquired. Hence, the Chinese are not essentially indispensable in the knowledge diffusion enterprise. Theoretically, knowledge diffusion becomes non-existent, through trade, when higher versions of the knowledge emanating from traded equipment have already been acquired from another source where similar equipment have been traded.

Notwithstanding these realities, the knowledge diffused from Chinese inventors to technicians of the Chinese agricultural machinery importers could be found useful and worthy of consideration. This is because the Chinese crop farming inputs were their first point of contact as far as knowledge diffusion on agricultural machinery is concerned and not because the Chinese agricultural machinery introduces new technological insights. Moreover, acknowledging the role of the Chinese inventors will not be out of place given the fact that it creates wider options of agricultural machinery with lower cost and has created expanded opportunities for a greater number of technicians to acquire more knowledge about agricultural machinery.

\subsection{Knowledge Diffusion in Ghana's Livestock Sub-sector}

In this subsection emphasis will be given to the poultry and the meat production industries striking out some semblances and unique traits in these industries, where necessary, as knowledge is diffused.

\subsubsection{Knowledge Diffusion in Ghana's Meat Production Industry}

Experiences by the meat processors also show a great deal of knowledge diffusion from China into Ghana's agricultural sector. The research participant recounted his experience about the knowledge he acquired from a Chinese firm on the appropriate thickness of the polythene he used to package his processed meat products. He accedes with his experience as follows

"Chinese equipment helps you grow and their platform of seeing products opens your eyes, and gives you insight and you can even be educated just corresponding or chatting with the Chinese company. Yea you say I want something that can package my meat for me, if it's a packaging company they will look at it oh okay then you have to use polythene of this gauge.... otherwise I don't even know who to talk to know the gauge of polythene I need. I got the knowledge in China; they tell you choose this knife they use it for this"

This enhances the longevity of storage of the meat. After learning about the appropriate thickness he informed the local producers of polythene about it that is what they produced for him whenever wished to purchase local polythene for meat packaging. In this sense, knowledge has been dispersed.

In sum, it can be established that the knowledge the actors gathered about Chinese agricultural input cover a wide range of issues. From the responses offered by the actors found in the meat processing industry as compared to the responses provided by actors in the agro-chemical industry it is apparent that some of the actors in the agricultural sector have gathered knowledge which has emerged as an outcome of the encounters they have had about Chinese capital mobility.

From the responses provided by the research participants from the diverse industries in the agricultural sector, five key observations can be made about the dynamics of knowledge diffusion from China into Ghana agricultural sector in the following regards:

a. The suitable equipment for a particular agricultural endeavor

b. The uses of an agricultural input

c. How an agricultural input is produced, installed and repaired?

d. How to use an agricultural input?

e. The right specifications of a particular agricultural input

\subsubsection{Knowledge Diffusion in Ghana's Poultry Drugs and Feed Supplement Industry}

Responses from actors in the poultry industry also that knowledge diffusion has been nonexistent. The organization which imports Chinese poultry feed and drugs

"Before I came to work here I was buying Chinese drugs I read more and I realized that they are all the same and what I see about drugs from China are not different from the drugs from Holland"(Official from Joeyeson Company)

This is similar to the experiences of the engineers at AESD who did not consider knowledge from China as non-existent because they have had exposure to other territorial origins of knowledge relative to traded products.

\subsection{Knowledge Diffusion in Ghana's Fisheries Subsector}

The level at which knowledge diffusion occurs in the fisheries subsector introduces some dynamics and complexities which require interrogations. This is because each industry in the fisheries sub-sector experiences its unique form and pattern relative to knowledge diffusion. However, given the fact that Chinese capital mobility into the fisheries subsector is very noticeable and dominant in the fish trawling industry issues about knowledge diffusion in the fisheries sub sector will be limited to that from China.

In this industry it is expected that knowledge diffusion could be taking place as the Ghanaians and the Chinese crew interact on board the fishing vessel. However, in the fish trawling industry, one fact remains; knowledge diffusion has been very minimal. This is evidenced by the response offered by all the stakeholders in the industry. On the part of an official of the fish trawling industry, for example,

"So there is very little transfer of knowledge from the Chinese to the Ghanaian crew".

This observation was corroborated by an official at the Marine Management Unit of the Fisheries Commission. She intimated that

"so when it comes to transferring the knowledge as in the techniques used for fishing, I will say on the personal 
level, you won't get a very high level efficiency"

The apparently low level of knowledge diffusion from China into the trawling industry consequently leads to a lot of unsharpened human resource in the fish trawling industry thereby rendering Ghana technically incapacitated to manage the fish trawling industry. This was clearly mentioned by a fish trawling industry player. He said,

"... we have a major problem of crew because we haven't built Ghanaian capacity to own and manage trawlers"

The low level of knowledge diffusion is largely attributed to a wide knowledge inequality gap between Ghanaian working in the fish trawling industry and the Chinese crew members. Even though Ghanaians could occupy middle level positions on the vessel there is a deficit in terms of the number of people required to occupy that position. Further, the implication of low level of knowledge diffusion and the absence of institutional efforts at building are the creation is a growing degree of middle level and top level human resource deficit thereby reducing employment opportunities for Ghanaians. Moreover, Ghanaians would not gain opportunities to occupy higher positions in the industry hence their ability to influence decisions, which could inure to their benefit, is inhibited and the benefits of knowledge diffusion adduced by [26] well as [17] with regard to innovative performance become illusive.

The interview also disclosed that Ghana does not have a known gear technologist within the Marine Management Unit Ministry of Fisheries and Aquaculture. Thus, there was no knowledge foundational basis which could have allowed the complex, heterogeneous and diverse processes [36] of adapting knowledge to take place between the Ghanaian and the Chinese crew members. This was intimated by an official from the Fisheries Commission as follows,

"we do have some of the Chief engineers which is like the third in command, most often being Ghanaians but they are just a few. Most Ghanaians are occupied are employed as dock workers so they do the sorting, they do all the... into brackets all the dirty work is done by the Ghanaians" (Member, Industrial Fish Trawling Association of Ghana).

This knowledge inequality gap between the Ghanaians and the Chinese crew members for which knowledge diffusion is seen to be on a minimal scale is a function of institutional lapse. Supporting this claim with evidence a participant rightly indicated that and provided one of the myriad of reasons as follows

"As a country we have a long time not developed the fisheries industry because the Regional Maritime University, I think, for lacks of patronage of their programs. Over a long period of time, Ghanaians have lacked the ownership of vessels and have not been trained too. And even those that are trained normally go for the training at the Maritime University because they may have contracts abroad and not because they really want to fish in Ghana" (Member, Industrial Fish Trawling Association of Ghana).

In a broader political context, there seem not to be any deliberate plan which is motivating enough to ensure transfer of knowledge from the Chinese to Ghanaians. The lack of deliberate plan is expressed in three folds. The first is weak training regime. This is evidenced in the words of the Fisheries Commission officer in the Marine Management Unit

"The Regional Maritime University likewise all other universities have not been able to produce enough technical people"

The second is an absence of any enquiry to ascertain the degree of diffusion, if they so exist, to establish real knowledge gaps. The Fisheries Commission officer in the Marine Management Unit, once again, indicated that

"No research has been done"

The third is the lack of enforcement on laws that could enhance knowledge diffusion. The Fisheries Commission officer in the Marine Management Unit, once again, indicated further that:

"Although the law requires that Chinese should speak in English, it is not entirely so practically"

Indeed, from the responses, it is clear that low level of knowledge diffusion is a function of the lack of deliberate plan by state institutions resonating the idea that argument that a successful knowledge diffusion regime relies on a more dynamic, participatory, collaborative system [35] as well as fundamental and structural characteristics [32] of the receiving society. It may be argued that under certain circumstances when there are no deliberate plans to ensure knowledge diffusion from China to actors in the fisheries sector, some informal methods could have been deployed to acquire the knowledge. One of these could have been the inscriptions on the equipment which could have enabled the actors to gain knowledge about the vessel. However, the inscriptions are in Chinese language. A fish trawling official hinted that:

"The inscriptions on the vessel are all in Chinese. Most of the equipment that came with the vessel too have their inscriptions in Chinese. And you realized that because China is not an English speaking country, so the Ghanaians there could not even read".

This was corroborated by an official of the Marine Management Unit of the Fisheries Commission

"although the law requires that that the Chinese should speak English, or should be able to communicate or should have some English as the... some level of knowledge in English, er... practically that is not entirely so right? Yeah it is not entirely so; not all of them can speak English"

Hence, the lower depths in knowledge diffusion is also fostered by language barrier faced by Ghanaians who work as crew members in Chinese vessels used for fish trawling. This observation is consistent with the findings of (43] and [44] which suggest that Chinese investments are usually associated with language barrier between Chinese managers and local employees in East Africa.

In addition to the language barrier, the administrative structure which puts the Chinese crew at the top management positions in the organizations which operate the vessels does 
not equally favor the diffusion of knowledge from China into the trawling industry. Essentially, the occupation of Ghanaians at the lower positions is attributable to the Ghanaian crew are not technically inclined. Expressed by an official from the fish trawling industry,

"You can have a Ghanaian as a second officer, and second engineer and normally do the other things and then the decision making, so the decision making is normally lopsided. So you have a very heavy top Chinese management in the crew. So normally you have the captain, the first engineer, the chief officer all being Chinese".

Hence, from a political economy perspective Chinese knowledge diffusion into Ghana's agricultural sector may fail because the imported technologies are not met with an appreciable level of knowledge by indigenous actors in the fish trawling sector. This buttresses the argument raised by [16] on the role of knowledge diffusion that it depends on, among others, the level of knowledge and innovation performance.

Table 3. Summary of Knowledge Diffusion Success Variations and Contextual Factors.

\begin{tabular}{llll}
\hline $\begin{array}{l}\text { Industries with Successful } \\
\text { Knowledge Diffusion }\end{array}$ & Contextual Reason & $\begin{array}{l}\text { Industries without Successful } \\
\text { Knowledge Diffusion }\end{array}$ & Contextual Reason \\
\hline Meat Production Industry & Non-technical Knowledge & Industrial Trawling Industry & $\begin{array}{l}\text { Structural Impediments } \\
\text { Exposure to other origins of } \\
\text { Agro-chemical Industry }\end{array}$ \\
$\begin{array}{llll}\text { Agricultural Equipment Industry } \\
\text { (Engineers with Importer) }\end{array}$ & $\begin{array}{l}\text { Non-exposure to other origins of } \\
\text { knowledge }\end{array}$ & $\begin{array}{l}\text { Agricultural Equipment } \\
\text { (Engineers with State Ministry) }\end{array}$ & $\begin{array}{l}\text { Exposure to other origins of } \\
\text { knowledge }\end{array}$ \\
\hline
\end{tabular}

Source: Author's Construction.

\section{Conclusions on Knowledge Diffusion from China Into Ghana's Agricultural Sector}

The dynamics of knowledge diffusion from China into Ghana's agricultural sector presents certain unique patterns upon which the process could be understood and applied. First, knowledge can be learnt through a deliberate effort of the knowledge producer. Secondly, knowledge can be learnt, albeit unplanned and unsolicited by the knowledge recipient; and third, knowledge can be learnt consciously but without the consent of the knowledge producer.

Knowledge as discovered is being diffused within various interactive processes. However, in all these contexts a key observable phenomenon is that arrays of mediums are being used to diffuse the knowledge from China into Ghana's agricultural sector. Some of the processes of knowledge diffusion are face to face in character while others are process of knowledge diffusion occurred through the use of mobile phone underpinned by the deployment of various social media platforms.

In such an instance the process of obtaining the knowledge using the mobile phone can occur either through calls or messaging. Hence, the linkages between the actors of knowledge diffusion are far more expressed with the introduction of ICT which does not only favor the process of knowledge diffusion but also enforces the creation of knowledge, indirectly. Indeed, the mode of transmission is determined by the context within which knowledge is generated.

Besides, it can be argued clearly that when actors from different territories meet knowledge is likely to be shared in more relational and interactive terms. Clearly then knowledge diffusion happens when knowledge is communicated through certain channels from members of one social system to another social system who do not share the same national territorial boundary with asymmetrical levels of knowledge.

As manifested in the discussions, there are varied contexts within which the knowledge diffusion from China has been promoted which include the increasing spate of technological advancement, state-initiated policy arrangement, linguistic parity, foundational knowledge and innovative abilities.

The nuances in the knowledge diffusion patterns show a clear absence of uniformity in the knowledge diffusion patterns. Actors in the food crop production subsector seem to have acquired some useful knowledge than actors in the industrial fish trawling sector and poultry production industry. In all cases the varied degree of diffused knowledge shows that the involvement of the state could be the defining factor in ensuring knowledge diffusion. Besides the innovative and adaptive power of individuals could play a role.

Evidently, these patterns of knowledge diffusion have enormous implications for policy formulation which make take into considerations the functionality or otherwise of the knowledge diffusion, the patterns of non uniformity and how these variations these variations could be seen to be generating some promising and challenging outcomes. By way of policy, it is apparent that Ghanaians, directly or indirectly involved in agriculture, are capable of adapting to diffused knowledge embedded in Chinese products. For that reason, there is the need to discover indigenes who can adapt to the diffused knowledge Chinese products and introduce support systems and appropriate environment to enable them boost production of local substitutes. In addition, the lack of adequate training of Ghanaians which impeded their capacity to repair Chinese equipment and their opportunity to occupy top managerial position would require some attention by building the absorptive capacity of Ghanaians in the industrial fishing industry. 


\section{References}

[1] Ghana Investment Promotion Authority (GIPA), (2017). Chinese Investments in Ghana (1997-2016). Ghana Investment Promotion Authority.

[2] Amanor, K. S and Chichava, S (2016) South-South Cooperation, Agribusiness, and African Agricultural Development: Brazil and China in Ghana and Mozambique, World Development, Volume 81, pp. 13-23. http://dx.doi.org/10.1016/j.worlddev.2015.11.021.

[3] Scoones, I., Amanor, K., Favareto, A. and Qi, G. (2016). “A New Politics of Development Cooperation? Chinese and Brazilian Engagements in African Agriculture" World Development, Vol. 81, pp. 1-12.

[4] Amanor, K. S. (2013) 'Global resource grabs, agribusiness concentration and the smallholder: Two West African case studies., Journal of Peasant Studies, Vol. 39, No. 3-4, pp. 731-749.

[5] Idun-Arkhurst, I. (2008). "Ghana's Relations with China", China in Africa Report No. 3, South African Institute of International Affairs, Johannesburg.

[6] Ansah, J. W and Afful, B. (2018). Understanding the Forms and Trends of Capital Mobility from China into Ghana's Agricultural Sector: From Neo-liberalism to Social Innovation Journal of Business and Enterprise Development, Vol. 8, No. 1, pp. 1-22.

[7] Engel, P. H. G (1990). "Knowledge Management in Agriculture: Building upon Diversity and Knowledge in Society". The International Journal for Knowledge Transfer, Vol. 3, No. 3, pp. 28-35.

[8] Polanyi, M. (1967). The Tacit Dimension. Routledge and Kegan Paul, London.

[9] Philip, K. (2015) "Producing Transnational Knowledge, Neoliberal Identities, and Technoscientific Practice in India" Tactical Biopolitics, Vol, 12, No. 1 pp. 66-89.

[10] Hanusch, H., MauBer, A. and Rahmeyer, F. (2009) "Knowledge Diffusion Processes: Theoretical and Empirical Considerations" https://d-nb.info/1010124269/34 Accessed 17th September, 2016.

[11] Angang, H. (2015) 'Embracing China's new normal' Foreign Affairs, Vol. 9, No. 4 (3) pp. 8-12.

[12] Kang, B. (2015). "What Best Transfers Knowledge? Capital, Goods, and Innovative Labour in East Asia", Institute of Developing Economies Discussion Paper, No. 538.

[13] Hayek, F. (1944). The Road to Serfdom, University of Chicago Press, Chicago.

[14] Marx, K. (1887) 1967. Capital: A Critique of Political Economy, Vol. 1. International Publishers, New York, NY.

[15] Rodriguez-Pose A. and Crescenzi R. (2008). Mountains in a Flat World: Why Proximity Still Matters for the Location of Economic Activity. Cambridge Journal of Regions, Economy and Society, Vol. 1, No. 1, pp. 371-388.

[16] Shaijumon, C. S. (2014). "Institutions and Technology Diffusion in Agriculture: Role of ISRO Village Resource Centers" European Scientific Journal, Vol. 10, No. 10, pp.
480-497.

[17] Purwaningrum, F., Beckhanov M., and Sepulveda, A. (2009). "The Role of Knowledge in Developing a Local Agricultural Value Chain: The Story of "White Gold" from Uzbekistan", Interdisciplinary Term Paper, Bonn International Graduate School for Development Research (BIGS-DR).

[18] Quinn, J. B., Anderson, P. and Finkelstein, S. (1996). "Leveraging Intellect", Academy of Management Executive, Vol. 10, No. 1, pp. 7-27.

[19] Krugman, P. (1991). Increasing Returns and Economic Geography, Journal of Political Economy, Vol. 99, No. 1, pp. 483-499.

[20] Coe D. \& Helpman E., (1995). "International R\&D Spillovers”. European Economic Review, pp. 859-887.

[21] Keller, W. (2002). "Trade and transmission of Technology Diffusion as Measured by Patent Citations", Economic Letter, Vol. 87, No. 1, pp. 5-24.

[22] Bitzer, J. and Geischecker, I. (2006). 'What Drives Traderelated R\&D Spillovers and Growth?, Economics Letters, Vol. 85, pp. 209-213.

[23] Aitken, B. and Harrison, A. (1999). 'Do Domestic Firms Benefit from Direct Foreign Investment? Evidence from Venezuela', American Economic Review, Vol. 89, No. 89, pp. 605-618.

[24] Javorcik, B. S. (2004). "Does Foreign Direct Investment Increase the Productivity of Domestic Firms? In Search of Spillovers through Backward Linkages". America Economic Review, Vol. 94, No. 3, pp. 605-627.

[25] Oettl, A. and Agrawal, A. (2008). "International Mobility and Knowledge Flow Externalities", Journal of Internal Business Studies, Vol. 39, No. 8, pp. 1242-1260.

[26] Audretsch, D. and Feldman M., (1996). Innovative clusters and the industry life cycle. Review of industrial Organization Vol. 11, pp. 253-273 Available at http://eprints.lse.ac.uk. Accessed $12^{\text {th }}$ October, 2015.

[27] Fujita, M. and Thisse (2002) Economics of agglomeration: Cities, industrial location, and regional growth. Cambridge University Press, Cambridge.

[28] MacGarvie, M. (2005). "The Determinants of International Knowledge Diffusion as Measured by Patent Citations". Economics Letters. Vol. 87, No. 1, pp. 121-126.

[29] Tseng, C. (2007). "Technological Innovation and Knowledge Diffusion in the BRICs Countries: Evidence using Patent Data”. Available at http://web.pu.edu.tw/ ib/activity/conference/2007/3-4.pdf. Accessed 12th September, 2016.

[30] Bathelt H., Malmberg A. and Maskell P. (2004). Clusters and knowledge: Local buzz, global pipelines and the process of knowledge creation. Progress in Human Geography, Vol. 28, No. 1 pp. 31-56.

[31] Ernst, D. (2005). "Technological Capabilities and Export Growth". In Technological Capabilities and Export success in Asia. Routledge, London.

[32] Ascani, A. Cresenzi, R. and Iammarino, S (2012). Regional Economic Development: A Review, SEARCH Working Paper, European Commission. 
[33] Sumberg, J., J. Thompson and Woodhouse, P. (2013). "The changing politics of agronomy research", Outlook on Agriculture Vol. 42, No. 2, pp. 81-83.

[34] Adekunle, C. P., Ashaolu, O. F. and Obinka, C. A. (2015). "Effect of Industrial Externalities on Technical Efficiency among Cassava-Based Farming Households in Ewekoro Local Government Area, Ogun State, Nigeria”, Nigerian Journal of Agriculture, Food and Environment, Vol. 11, No. 4 pp. 82-89.

[35] Asefa, S., Alemneh, D. G. Roriss, A. (2014) 'Diffusion of Scientific Knowledge in Agriculture: The Case of Africa', Agricultural Information Worldwide, Vol. 6, pp. 34-47. Available at http://journals.sfu.ca. Accessed 12th March, 2016.

[36] Roeling, N. and Filert E. (1994) "Transforming Extension for Sustainable Agriculture, The Case of Integrated Pest Management in Rice in Indonesia", Agriculture and Human Values, Vol. 11, No. 2, pp. 125-146.

[37] Long, N. (2001). Development Sociology: Actors Perspective. Routledge, London.

[38] Thorne, S. (2000). "Data Analysis in Qualitative Research", Vol. 3, No. 1 pp. 68-70. Available at http://ebn.bmj.com/content/. Accessed $14^{\text {th }}$ July, 2015.
[39] Mauthner N. S. and Doucet, A. (2003). "Reflexive Account and Accounts of Reflexivity in Qualitative Data Analysis", Sociology, Vol. 37, No. 3, pp. 413-431.

[40] Almeida, P. and Kogut, B. (1999) 'Localization of Knowledge and Mobility of Engineers in Regional Networks', Management Science, Vol. 45, No. 7, pp. 905-917.

[41] Urmetzer, S., Schlaile, M. P., Bogner, K. B., Mueller, M. and Pyka, A. (2018) Exploring the Dedicated Knowledge Base of a Transformation towards a Sustainable Bioeconomy. Sustainability, 10 (6), 1-22.

[42] Agola, N. O. (2016) Technology Transfer and Economic Growth in Sub-Sahara African Countries, Springer, Verlag Berlin Heidelberg DOI 10.1007/978-3-662-49557-5_2.

[43] Baah, A. Y and Jauch, H. (2009). Chinese Investments in Africa: A Labour Perspective. Africa Labour Research Network.

[44] Shi, X., Chen, M. and Hoebink (2017) Knowledge Transfer in East Africa, (eds) Kathryn Batchelor and Xiaoling Zhang, China Africa Relations: Building Images through Cultural Cooperation, Media Representation and Communication. Routledge: 220-247. 